This is the final peer-reviewed accepted manuscript of:

Prati, G., Marín Puchades, V., \& Pietrantoni, L. (2017). Cyclists as a minority group? Transportation Research Part F: Traffic Psychology and Behaviour, 47, 34-41. https://doi.org/10.1016/j.trf.2017.04.008

The final published version is available online at:

https://doi.org/10.1016/j.trf.2017.04.008

(C) 2017. This manuscript version is made available under the Creative Commons AttributionNonCommercial-NoDerivs (CC BY-NC-ND) 4.0 International License (http://creativecommons.org/licenses/by-nc-nd/4.0/) 


\author{
Cyclist as a Minority Group? \\ Gabriele Prati, Víctor Marín Puchades, and Luca Pietrantoni \\ Department of Psychology, University of Bologna (Italy)
}

Corresponding author

Gabriele Prati, Dipartimento di Psicologia, Università di Bologna, Viale Europa 115, 47521

Cesena (FC), Italy; Tel.: +39 0547338507; fax +39.0547338503 (fax). Email:

gabriele.prati@unibo.it.

\title{
Acknowledgements
}

This work was supported by the European Commission under the Grant [number 635975]. Cofunded by the Horizon 2020 Framework Programme of the European Union (2014-2020) under contract number: 635975 Project XCYCLE. 


\begin{abstract}
In the social science, several definitions of minority group can be found. The definitions include different aspects such as power/status, number, distinctiveness, social category, group context, dispositions, and discrimination. Compared to motorized road users, cyclists are considered vulnerable road users because they lack physical protection. We argue that such definition does not capture the social and cultural aspects that characterize the membership within the group of cyclists. We offer arguments and reflections based on recent literature advocating that cyclists may share some features of the experience of minority groups. Although cyclists differ from other minorities in important respects, they manifest many of the characteristics by which minority groups are defined.
\end{abstract}

Keywords: cyclist, minority, vulnerable road user, driver, traffic, road, safety, cycling, identity, inequality, social movements 


\section{Cyclist as a Minority Group?}

Bicycle use as a mode of transport is associated with population-level health benefits (Garrard, Rissel, \& Bauman, 2012; Götschi, Garrard, \& Giles-Corti, 2016; Kelly et al., 2014) as well as with reduced traffic congestion, air and noise pollution, and greenhouse gas emissions through reduced fossil fuel consumption (de Nazelle et al., 2011; Macmillan et al., 2014; Xia, Zhang, Crabb, \& Shah, 2013). However, safety considerations contribute as barriers to bicycle use and promotion (Jacobsen \& Rutter, 2012). Cyclists are defined as vulnerable road users because they are unprotected by an outside shield from other motorised traffic (OCDE/OECD, 1998). Furthermore, motorized vehicles have greater mass and speed compared to bicycles (Wegman, Zhang, \& Dijkstra, 2012). For these reasons, motorized vehicles, with heavier machines and higher speeds, may present a danger to cyclists. Indeed, risks for cyclists are generally higher than those for motorists (Mindell, Leslie, \& Wardlaw, 2012). Haworth and Debnath (2013) have defined cyclists as minority road users because they are physically smaller, less visible, without physical protection, less stable, and more affected by road surface irregularities in comparison with dual track vehicles.

The burden of road traffic fatalities and injuries on cyclists may be not only the results of physical factors (e.g., lack of outside shield). Historical, social, and cultural factors may also play a role. The central thesis of this article is that cyclists as a group of road users been relegated to a secondary place. In short, cyclists may share aspects of the experience of minority groups. There is evidence of discriminatory treatment (e.g., yielding behaviour at crosswalks) and disproportionate safety outcomes (e.g., overrepresentation in pedestrian-vehicle collisions) for individuals belonging to ethnic minorities (Goddard, Kahn, \& Adkins, 2015; Mather \& DeLucia, 2007). Although the notion that cyclists comprise a minority group comparable to more obvious 
minorities (racial, ethnic, and religious minorities) was never articulated, Granville, Rait, Barber, and Laird (2001) investigated the extent to which cyclists were seen as being equal or unequal to other road users.

The present article draws on social science theory and empirical research to describe and explain the status of cyclists compared to other motorized road users. The current article is not a systematic review of the existing literature on topics such as cyclists' perceptions, cycling takeup, perceptions of cycling. Rather, the identified literature was examined and used to document our conceptualization of cyclists as minority road users, as opposed to only vulnerable road users. In other words, the aim of this article is to promote scientific discourse that challenges the current viewpoint on the status of cyclists compared to other motorized road users by applying definitions of minority group based on recent transport literature. First of all, the definition of minority group in the social science are briefly reviewed. Next, a discussion of whether cyclists may share some features of the experience of minority groups is offered.

\section{How do we define minority groups?}

The definition of minority would initially seem obvious. Numerically small groups are defined as minorities, whereas groups with the greatest number of members are majorities. This numeric conception of minority status is very common in the bulk of experimental research on minority-majority relations (Kerr, 2002; Simon, Aufderheide, \& Kampmeier, 2008). However, numerical asymmetries do not invariably signify status or power asymmetries (Moscovici, 1994). This concept can be illustrated by taking some examples of groups often identified as minorities. First, in several societies, women would be considered a (social) minority despite the fact that they compose more than half of the population. Similarly, large, yet powerless groups (e.g. Blacks during apartheid in South Africa) would have been considered a minority (Tajfel, 1978). 
Indeed, the term majority-minority population has been used to indicate a population in which more than half of its people belong to a minority group. In this regard, we could also mention the distinction between powerless populace — a minority group that is numerically large but powerless — and subjugated — a minority group that is numerically small and powerless (Seyranian, Atuel, \& Crano, 2008). Thus, it is difficult to argue that numeric size is the only or the main feature that characterizes minority groups.

In the sociological literature, minorities are thought to be held in low esteem by the majority and to experience discrimination and unequal distribution of power and resources (Simpson \& Yinger, 1985). The experience of prejudice and discrimination are central in some conceptualizations of minority such that it has been proposed its replacement by the term oppressed group (Meyers, 1984).

Such conceptualizations resemble those reported in the law literature: "[Minorities are] groups of individuals that, without being necessarily less in number than others (think of women), are for historical, economic, political or other reasons in a position of disadvantage (of subordination, inferiority in power, etc.) compared to other groups of the same society" (Torbisco Casals, 2006, p. 23).

Some scholars highlighted the complexity associated with defining minority groups and proposed several criteria. For instance, according to Wagley and Harris (1958, p. 10) minorities have the following five characteristics:

(1) "minorities are subordinate segments of complex state societies;

(2) minorities have special physical or cultural traits which are held in low esteem by the dominant segments of the society; 
(3) minorities are self-conscious units bound together by the special disabilities which their members share and by the special disabilities which these bring;

(4) membership in a minority is transmitted by a rule of descent which is capable or affiliating succeeding generations even in the absence of readily apparent physical or cultural traits;

(5) minority peoples by choice or necessity, tend to marry within the group".

The first three of the five characteristics may apply to most of the minority groups (e.g., ethnic, sexual, or religious minorities), while the fourth and the fifth characteristics can only be applied to a specific subset of minority groups. According to Tajfel (1981), there are both internal (e.g., stereotypes, self-consciousness, social movements) and external (e.g., power, social status, unequal distribution of resources) criteria of minority membership. More recently, Seyranian et al. (2008) proposed a multifaceted conceptualization of majority and minority groups along eight dimensions: power (i.e., group dominance, superiority, status, and influence over others), number (i.e., size of the group), distinctiveness (i.e., similarities or differences with other groups), social category (i.e., group types in society, usually nouns), group context (i.e., social, political, or economic circumstances of a group), dispositions (i.e., traits associated with minority groups), and being the source (i.e., how the group perceived or treated other groups) or target (i.e., how a group was treated or perceived by other groups) of behaviour. Although there are no consensual definitions of minority in social science, in our brief review we have indicated the most important dimensions that are relevant to minority groups. Next, we consider the question as to whether each of these dimensions can be used to describe the condition of cyclists. 
The number of cyclists is lower than that of drivers in most countries. For instance, a slim majority (54\%) of EU citizens said they used a car as their main mode of transport, while cycling was reported as the most common mode of daily transport by a minority (8\%) of EU citizens (European Commission, 2014). In North America, the bike share of total trip is around 1\% (Pucher, Buehler, \& Seinen, 2011). Nevertheless, there exist large differences among countries in cycling levels (Buehler \& Pucher, 2012) that would skew the importance of cyclists' numerousness as a factor in their definition as minority. This way, in the Netherlands, $43 \%$ of the nationals acknowledge using the bicycle at least once a day, whereas in Malta, only $1 \%$ of them do so (European Commission, 2013). Fear of cycling could be a significant barrier to cycling (Horton, 2007) and cycling safety is positively related to the cycling levels (Jacobsen, 2003). However, there is some evidence on the extent to which the perception of cyclists and cycling varies according to differences in cycling levels across countries. Although the SARTRE 4 survey showed that cyclists' risk perception does not seem to be related to cycling levels in general, it also showed that the lowest levels of cyclists' risk perception among all the countries examined was found in countries with relatively low cycling levels, such as Spain, Israel and Austria (Antov et al., 2012). Chataway, Kaplan, Nielsen, and Prato (2014) showed that cyclists riding in an emerging cycling city (Brisbane, Australia) are more likely to perceive mixed traffic infrastructure layouts as less safe and feel more fear of traffic compared to cyclists in an established cycling city (Copenhagen, Denmark). Also, there are differences across countries in the degree to which cyclists are satisfied with the route they usually take, with the speed and traffic volume, with the road infrastructure (cycle paths, street lightning) and with safety in general (Antov et al., 2012). It is interesting to note that satisfaction with these aspects among cyclists tends to be higher in countries with high cycling levels (e.g., the Netherlands, Sweden, 
Finland, and Germany) and lower in countries with low cycling levels (e.g., Cyprus, Estonia, and Greece). However, there are notable exceptions to this trend. For instance, Hungarian cyclists are not satisfied despite the high levels of cycling. Skinner and Rosen (2007, p. 83) claim that "in a few locations, where cycling has a higher profile, bicycle users are more accepted; in others, where cycling on the road is rare, they are less well tolerated, and attitudes towards cycling can be hostile and even threatening". Cycling levels may be related to the descriptive norm concerning cycling, that is, the perception of how people behave in a given situation, regardless of the approval of such behaviour (Aronson, Wilson, Akert, \& Sommers, 2015). Among Swedish people, descriptive norm concerning cycling was a significant and important predictor of intention to use a bicycle (Eriksson \& Forward, 2011). A study conducted in Austria showed that people who have many friends who cycle (descriptive norm concerning cycling) were more likely to be regular or irregular cyclists (Titze, Stronegger, Janschitz, \& Oja, 2008). In addition, in a sample of Flemish adults, it was found that cyclists were more likely to have a cycling partner and relatives who cycle (de Geus, De Bourdeaudhuij, Jannes, \& Meeusen, 2008). In addition, cycling levels could also be associated with subjective norms favouring cycling, which refer to the 'likelihood that important referent individuals or groups approve or disapprove of performing a given behaviour' (Ajzen, 1991, p. 195), as well as with more positive attitudes towards cycling.

Several scholars have reported differences in power between cyclists and other motorized road users. Basford, Reid, Lester, Thomson, and Tolmie (2002) found that drivers used to attribute cyclists the lowest place in the road user hierarchy. Moreover, cyclists are generally not accepted as equal road users (Granville et al., 2001). Cavacuiti et al. (2013) reported that cyclists felt they were "second-class" citizens that did not deserve as much road space as cars. 
Nevertheless, they felt that they deserved (at least) an equal treatment. According to Pucher, Komanoff, and Schimek (1999), in North America, bicycling was hindered due to infrastructure and legal status of cyclists, and because many drivers (and police officers) were unaware of cyclists' rights to use ordinary roads.

Regarding the social, political, and economic circumstances of cyclists, it has been argued that during the majority of the twentieth century, roads were adapted to "contemporary public demands and interests [...] which resulted in urban streets being reconstructed and used as a place fundamentally for motor vehicles" (Karndacharuk, Wilson, \& Dunn, 2014, p. 194). In most developed countries, a car-centred culture is dominant and lifestyles are built on the cultural assumption of the ownership and use of motorized vehicles (Aldred \& Jungnickel, 2014). In addition, in most developed countries, societies are socially and spatially dominated by motor vehicles and car-dominated environments are likely to become hostile social environment for cyclists (Aldred, 2013a). There is also evidence that one out of three cyclists are often, very often or always annoyed by car drivers. However, we should acknowledge that the percentage of cyclists that are annoyed by other road users such as car drivers or motorcyclists vary according to the cycling levels of the country (Antov et al., 2012). Finally, cyclists recognize that the sociocultural context, defined as the social values and attitudes, transport culture and norms, and the underlying economic and political factors, is negative for cycling (Daley, Rissel, \& Lloyd, 2007). Such circumstances can also be interpreted as differences in power of motor vehicle drivers as well as their number. Taken together, these aspects seems to suggest that cyclist are in a position of disadvantage (Torbisco Casals, 2006), constitute a subordinate segment of complex state societies (Wagley \& Harris, 1958), and may experience an unequal distribution of power and resources (Simpson \& Yinger, 1985). 


\section{Distinctiveness, Social Category, and Dispositions}

According to Tajfel (1981), stereotypes are central in the definition of the subjective characteristics of a membership in a minority group. There is some work which supports the idea that people hold negative stereotype of the typical cyclist (Aldred, 2013a, 2013b; Gatersleben \& Haddad, 2010). In their qualitative study, Davies, Halliday, Mayes, and Pocock (1997) found that the social representation of bicycling and bicyclists in the UK are mainly negative. According to Pucher et al. (1999), cyclists were seen as too poor to purchase a car, anti-auto, eccentric, or deviant. Basford et al. (2002) revealed that drivers associate negative traits to bicyclists such as irresponsible (due to a lack of training or formal commitment to road rules), unpredictable or erratic (e.g., not signalling intentions), arrogant (cyclists were perceived as holding careless attitudes towards their own safety or holding other road users accountable for their own safety) and inconvenient (e.g., delaying to motorized road use). As a matter of fact, in the recent trend towards fully-automated vehicles, cyclists are seen by car manufacturers as a threat because of their unpredictability and potential to be identified (by a hypothetical automated car) as behaving as either pedestrians or cars (Reid \& LeBeau, 2016).

Drivers tend to think of themselves as distinct and different from the typical cyclist (Gatersleben \& Haddad, 2010) and drivers view bicyclists as the 'out group' - with many diverse behavioural characteristics from other road users (Basford et al., 2002). The main reasons given refer to cyclists not respecting road rules, and therefore, acting differently from other road users. Similarly, other studies revealed that cyclists are seen by drivers as risk takers and law breakers (Daley \& Rissel, 2011; Granville et al., 2001). Because of this representation, many drivers perceived cyclists as "their own worst enemy" (Granville et al., 2001). This negative representation of cyclists suggests the existence of traits which are held in low esteem by the 
majority (Wagley \& Harris, 1958) and of the possession of common some socially relevant characteristics (Tajfel, 1981).

There is some evidence of feelings of group identity and community among people who cycle mainly for similar purposes (Bartle, Avineri, \& Chatterjee, 2013; Fincham, 2007). In addition, consistent with the social identity theory (Tajfel \& Turner, 1986), which states that people perceive members of their own group more positively than members of other groups, drivers who are also cyclists have a more positive view of cyclists and behave more considerately towards them than drivers who are not cyclists (Basford et al., 2002; Gatersleben \& Haddad, 2010; Granville et al., 2001). Finally, Aldred (2013a, 2013b) showed that bicycle use can produce disadvantaged and stigmatized social identities in Goffman's terms. Specifically, cyclists face a dual stigma since they are defined as either road warriors (too competent to need resources or protection) or as unskilled and incompetent (and as such not deserving resources or protection). Elements of negotiation, disavowal, and challenge have been found in the strategies of identity management used by cyclists. Taken together, cyclist can be regarded as selfconscious units (Wagley \& Harris, 1958) or social groups with a feeling of common membership of a minority (Tajfel, 1981). Nonetheless, we are not assuming that cyclists are themselves a homogeneous group. For instance, cyclists may differ between regular, occasional, and nonriders, and belong to both categories of drivers and cyclists. In addition, different riding subcultures are reported such as recreational riding, cycling for sport and exercise, and transport/commuter cycling. Finally, we note that some cycling advocacy circles contest the use of the term "cyclist" because it emphasizes personal characteristics linked to stereotypes such as "risk takers" and "law breakers" (Daley \& Rissel, 2011). Rather, the use of cycling as a normal activity open to everyone may be preferable. 
According to the social identity theory (Tajfel \& Turner, 1986), people have a variety of social identities, which are more or less salient in different contexts. Like other transport-related identities, cyclists or cycling identities are in a dynamic relationship with other social identities and their salience and meaning depend on the context (Aldred, 2013a; Skinner \& Rosen, 2007).

Within a context socially and spatially dominated by motor vehicles, cyclists or cycling identities may exist by comparison with, and in competition with motorised modes of transport (Aldred, 2013a).

\section{Target of behaviour}

Several behaviours towards cyclists have been studied, mostly aggression, negative attitudes, and warnings from the part of other motorized road users (Aldred \& Crosweller, 2015; Fruhen \& Flin, 2015; Johnson, Oxley, Newstead, \& Charlton, 2014). For instance, Aldred and Crosweller (2015) investigated cyclists' incidents in United Kingdom and found that the $4.8 \%$ of them involved deliberate harassment or aggression by drivers (e.g., revving) and estimated that harassment from other road users took place on a monthly basis. There is evidence that drivers that do not cycle held more negative attitudes towards cyclists compared to people cycling regularly or occasionally (Daley \& Rissel, 2011; Fruhen \& Flin, 2015). However, we want to make clear that differences may exist among cyclists or people who cycle. For instance, the experiences of abuse on the road may differ between male and female cyclists (Aldred, 2013a).

\section{Source of behaviours}

In the last century, cycling advocacy has become increasingly prominent in Europe and in other western countries. There have been concerted movements consciously both to defend and to promote cycling as an everyday practice. Cycle activism was aimed at resource mobilization in order to create value and identity (Aldred, 2012). 
Aldred (2013b) has analysed cycling advocacy in the UK, particularly in London and Edinburgh. Drawing on social movement theory, she explored how the creation of "pop-up campaign' Londoners on Bikes formed to pressure the 2012 London mayoral candidates over cycling issues. Cycling has been framed politically and cyclist groups were trying to generate a positive cycling identity in the context of stigma. In negotiating these issues, core activists drew upon their experience within other movements, including feminist and environmental campaigns. The author concludes that the campaign made both distributional (issue-based) and recognition (identity-based) claims, seeking to influence cycling cultures and identities as well as changing cycling infrastructures. One of the most representative examples of international cycling activist phenomena is the Critical Mass (Cycle Ride). This movement reacts to the dominance of the car and has aimed to bring about political debate on urban civility (i.e., regarding drivers' behaviours towards cyclists) by organizing clearly identifiable (and distinct) rides (Parry, 2015). The existence of these social movements may be reflected in a self-awareness of being a minority (Tajfel, 1981).

Moreover, cyclists not only do represent a source of mass social behavior such as the above mentioned. A study conducted in Denmark by the Danish Cyclists' Federation and IS IT A BIRD (Cycling Embassy of Denmark, 2015) found that different road users, cyclists included, tended to perceive several cyclists behaviors as problematic (e.g., red light running, not using lights in the dark). Moreover, a $42 \%$ of the participants reported having been shouted at by cyclists and a $36 \%$ having got the finger by cyclists.

\section{Cyclists as Minority Road Users and Differences among Countries}

It is clear that cyclists or people who cycle differ from other minorities in important aspects. First, mobility choices and behaviour are only one part of people's life and, to some 
extent, can be changed. Behaviour and identity may be disentangled, because travel behaviour and mode choice are more related to "what you do" and not "who you are." As for other minorities, social and contextual factors define when people with a specific behaviour are understood to have a personal attribute or a social identity. For instance, where cyclists are treated as equal road users, perceptions of cyclists and cycling identities may be different and perhaps less salient. Second, the sense of community and in-group identity with other cyclists may be less salient when the use of bicycle is just a routine transport choice (Bartle et al., 2013). Third, research has shown that people hold also positive stereotypes of bicyclists (Gatersleben \& Haddad, 2010), though positive stereotypes exist about other minorities.

Notwithstanding these differences, there are cultural and social aspects that are not captured by the definition of cyclists as vulnerable road users. In this article, we argued whether cyclists can reasonably be viewed as a minority group because they display some of the characteristics by which minority groups are defined. Consistent with the multifaceted conceptualization of majority and minority groups proposed by Seyranian et al. (2008), several dimensions of the experience of minority groups were addressed: number, distinctiveness, social category, group context, dispositions, and being the source or target of behaviour.

Cyclists may feel less safe because "those in a minority generally perceive themselves to be less safe than those in the majority" (Horton, 2007, p. 136). Indeed, previous research showed that cycling was perceived as more dangerous than driving (Lawson, Pakrashi, Ghosh, \& Szeto, 2013). The majority is supported by the dominant car-centred culture as compared to bicycle culture. Indeed, cyclists, as non-car users, may feel marginalized by society (Pooley et al., 2011). Moreover, cycling take up levels also influence the objective risk of cycling and therefore the degree of disadvantage that cyclists suffer. Such influence is explained by the safety-in-numbers 
effect, which shows that the increase in cycling volumes is not followed by a proportional increase in bicycle crashes, but by a proportionally smaller increase (Elvik \& Bjørnskau, 2017), or even a reduction thereof, as seen in the decrease of cyclists' crashes in Denmark (Cycling Embassy of Denmark, 2015). Thus, higher take up might involve a betterment in cyclists' condition of disadvantaged minority by means of a reduction of crash risk either by a prior or posterior increase in cycling safety. A possible cause for the increase in cycling levels and safety could be the previous improvement of perceived cycling safety, attractiveness by the construction and implementation of cycling infrastructures. Nevertheless, the causal mechanism yielding the safety-in-numbers remains partially unknown (Elvik \& Bjørnskau, 2017). In fact, the characteristics of cyclists might differ depending on the number of cyclists. It is well-known that many people hesitate to cycle, or abstain entirely from it, in complex city traffic that they regard as hazardous and difficult to handle (Chataway et al., 2014; Tsakas, Matsoukis, \& Bernhoft, 2010). In the most demanding traffic environments, only those cyclists who tolerate the risk and have would opt for cycling.

Perceptions of cyclists or cycling identities may differ across countries based on cycling levels. More generally, the societal acceptance of cycling as a mode of transportation by one's community plays an important role (Willis, Manaugh, \& El-Geneidy, 2015). Social acceptance, subjective norms, and attitudes towards cycling could differ at national, community and group levels and are core elements of bicycling culture.

The levels of bicycling culture play an important role in shaping cycling practices as well as the impact of policy interventions (Aldred \& Jungnickel, 2014). The cultural norms and beliefs of most developed countries concerning car use has contributed to the consideration of cyclists as 'second class' road users (Parkin, Ryley, \& Jones, 2007). To be considered as equal 
road users, cyclists deserve special consideration. The reason is that treating essentially different road users in an identical fashion would violate the principles of equality and non-discrimination. If cyclists are only considered as vulnerable road users, segregation between motor vehicles and bicycles seems the best option. The main aim of segregation is to minimize the risk of conflicts. Although segregation between motor vehicles and bicycles have many advantages, complete segregation is expensive and arguably unfeasible. If anything, if cyclists are considered a minority group, the integration principle (as opposed to segregation), exemplified by the concept of urban shared spaces (Biddulph, 2012; Hamilton-Baillie, 2008a, 2008b; Karndacharuk et al., 2014), becomes another attractive option. Following this perspective, the focus is social integration and inclusion of all road users which are stimulated to legitimately use the same road space in a safe and efficient manner. What is evident in this perspective is a shift towards recognizing the need to reduce the dominance of the motor vehicle by promoting sustainable and safe transport for all users.

\section{Shared Space vs. Segregation}

Cycling infrastructure also embodies an important contextual factor related to safety perception. Indeed, previous research has found that the presence of cycling infrastructure is associated with a reduction of risk perception and fear of traffic (Chataway et al., 2014; Møller \& Hels, 2008). It is important, therefore, that infrastructure design takes into account perceptions of cycling/cyclists, and safety. As previously mentioned, there is evidence that mixed traffic is perceived as more dangerous by cyclists riding in an emerging cycling city than those riding in an established cycling city (Chataway et al., 2014). In other words, if cycling in mixed traffic means being squeezed between the traffic flow and parked cars, segregated cycle lanes may be preferable by cyclists because they are perceived as safe infrastructure layouts. Tsakas et al. 
(2010) compared the promotion of cycling in cities with two different cycling levels, Copenhagen and Patras, and concluded that the low level of cycling culture in Patras has led to the suggestion of bicycle tracks totally separated from motorized vehicles. It should be noted that one of the lessons that can be learned from countries with higher cycling levels (i.e., The Netherlands, Denmark, and Germany) is the successful combination of separate cycling facilities along heavily travelled roads and at intersections with traffic calming of most residential neighbourhoods (Pucher \& Buehler, 2008). In traffic-calmed streets, car speeds are restricted (e.g., to $30 \mathrm{~km} / \mathrm{hr}$ ) and cyclists have priority over motorists. Thus, the integration principle may be preferred in lightly travelled, traffic-calmed residential streets, making them ideal for cycling, even without separate cycling facilities. Along heavily travelled roads by motorized vehicles and at intersections, the segregation principle may be appropriate.

\section{Conclusion}

In the present article, we proposed a conceptualization of cyclists as minority road users, as opposed to vulnerable road users. We argue for a conceptualization of cyclists as minority road users that includes not only the lack of physical protection (typical feature of vulnerable road users), but also the social and cultural factors that shape the membership within the group of cyclists or people who cycle. As we advocated in the present study, there are several arguments supporting the view of cyclists or people who cycle as a minority in relationship with drivers. We reviewed literature providing evidence of cyclists or people who cycle as a minority group following the conceptualization of majority and minority groups along eight dimensions provided by Seyranian et al. (2008). Specifically, there is evidence that cyclists or people who cycle tend not to be seen and treated as equal road users (distinctiveness, dispositions, and power), tend to be numerically small (number), constitute a social category, report negative 
social, political, or economic circumstances (group context), and are the source and target of behaviour. Nevertheless, compliance with the conceptualization of minority groups depends on several contextual characteristics (e.g., cycling levels, available infrastructure and protection, stereotypes and prejudice towards people who cycle, risk perception) that vary among different countries or cities. For instance, in small cities in the Netherlands such as Houten and Groningen, the majority of trips within city are made by bicycle (Handy, Heinen, \& Krizek, 2012). Although there is some evidence that supports the view that cyclists or people who cycle could be considered a minority in relation to drivers, future studies may investigate what are the most important characteristics of a minority group in determining the attractiveness of cycling, and use them as leverage to design interventions to increase it. Finally, future research should investigate the possible minority-majority influence process. Minority members do not solely function as non-conforming targets but also challenge the validity of the majority position, create pathways leading toward divergent thought processes by stimulating a search for more information and a multiple-perspective approach to (traffic) solutions. Moreover, minorities perceived as especially consistent in the advocacy of their views can be especially influential. Social influence processes among road users (Fraboni, Marin Puchades, De Angelis, Prati, \& Pietrantoni, 2016) should also be taken into account in future studies on travel behavior and road safety. 


\section{References}

Ajzen, I. (1991). The theory of planned behavior. Organizational Behavior and Human Decision Processes, 50(2), 179-211.

Aldred, R. (2012). The role of advocacy and activism. In J. Parkin (Ed.), Cycling and Sustainability (pp. 83-108). Bingley, UK: Emerald Group Publishing Limited.

Aldred, R. (2013a). Incompetent or too competent? Negotiating everyday cycling identities in a motor dominated society. Mobilities, 8(2), 252-271. doi:10.1080/17450101.2012.696342

Aldred, R. (2013b). Who are Londoners on Bikes and what do they want? Negotiating identity and issue definition in a 'pop-up' cycle campaign. Journal of Transport Geography, 30, 194-201. doi:http://dx.doi.org/10.1016/j.jtrangeo.2013.01.005

Aldred, R., \& Crosweller, S. (2015). Investigating the rates and impacts of near misses and related incidents among UK cyclists. Journal of Transport \& Health, 2(3), 379-393. doi:http://dx.doi.org/10.1016/j.jth.2015.05.006

Aldred, R., \& Jungnickel, K. (2014). Why culture matters for transport policy: The case of cycling in the UK. Journal of Transport Geography, 34, 78-87. doi:http://dx.doi.org/10.1016/j.jtrangeo.2013.11.004

Antov, D., Banet, A., Barbier, C., Bellet, T., Bimpeh, Y., Boulanger, A., . . Zavrides, N. (2012). European road users' risk perception and mobility: The SARTRE 4 survey. Retrieved from http://www.attitudes-roadsafety.eu/home/publications/

Aronson, E., Wilson, T. D., Akert, R. M., \& Sommers, S. R. (2015). Social Psychology (9 ed.). Boston: Pearson.Education, Inc.

Bartle, C., Avineri, E., \& Chatterjee, K. (2013). Online information-sharing: A qualitative analysis of community, trust and social influence amongst commuter cyclists in the UK. 
Transportation Research Part F: Traffic Psychology and Behaviour, 16, 60-72. doi:http://dx.doi.org/10.1016/j.trf.2012.08.013

Basford, L., Reid, S., Lester, T., Thomson, J., \& Tolmie, A. (2002). Drivers' perceptions of cyclists. Department for Transport.

Biddulph, M. (2012). Radical streets? The impact of innovative street designs on liveability and activity in residential areas. URBAN DESIGN International, 17(3), 178-205. doi:10.1057/udi.2012.13

Buehler, R., \& Pucher, J. (2012). International overview: Cycling trends in Western Europe, North America, and Australia. In J. Pucher \& R. Buehler (Eds.), City Cycling (pp. 9-30). Cambridge, MA: MIT Press.

Cavacuiti, C., Ala-Leppilampi, K. J., Mann, R. E., Govoni, R., Stoduto, G., Smart, R., \& Locke, J. A. (2013). Victims of road rage: A qualitative study of the experiences of motorists and vulnerable road users. Violence and Victims, 28(6), 1068-1084.

Chataway, E. S., Kaplan, S., Nielsen, T. A. S., \& Prato, C. G. (2014). Safety perceptions and reported behavior related to cycling in mixed traffic: A comparison between Brisbane and Copenhagen. Transportation Research Part F: Traffic Psychology and Behaviour, 23, 32-43. doi:http://dx.doi.org/10.1016/i.trf.2013.12.021

Cycling Embassy of Denmark. (2015). New study on cyclist behavior. Retrieved from http://www.cycling-embassy.dk/2015/06/22/new-study-on-cyclist-behaviour/

Daley, M., \& Rissel, C. (2011). Perspectives and images of cycling as a barrier or facilitator of cycling. Transport Policy, 18(1), 211-216. doi:http://dx.doi.org/10.1016/j.tranpol.2010.08.004 
Daley, M., Rissel, C., \& Lloyd, B. (2007). All dressed up and nowhere to go? A qualitative research study of the barriers and enablers to cycling in inner Sydney. Road and Transport Research, 16(4), 42-52.

Davies, D., Halliday, M. E., Mayes, M., \& Pocock, R. L. (1997). Attitudes to cycling: A qualitative study and conceptual framework. Crowthorne: TRL.

de Geus, B., De Bourdeaudhuij, I., Jannes, C., \& Meeusen, R. (2008). Psychosocial and environmental factors associated with cycling for transport among a working population. Health Education Research, 23. doi:10.1093/her/cym055

de Nazelle, A., Nieuwenhuijsen, M. J., Anto, J. M., Brauer, M., Briggs, D., Braun-Fahrlander, C., . . Lebret, E. (2011). Improving health through policies that promote active travel: A review of evidence to support integrated health impact assessment. Environment International, 37(4), 766-777. doi:10.1016/j.envint.2011.02.003

Elvik, R., \& Bjørnskau, T. (2017). Safety-in-numbers: A systematic review and meta-analysis of evidence. Safety Science, 92, 274-282. doi:10.1016/j.ssci.2015.07.017

Eriksson, L., \& Forward, S. E. (2011). Is the intention to travel in a pro-environmental manner and the intention to use the car determined by different factors? Transportation Research Part D: Transport and Environment, 16(5), 372-376.

doi:http://dx.doi.org/10.1016/j.trd.2011.02.003

European Commission. (2013). Attitudes of Europeans towards Urban Mobility. Special Eurobarommeter 406/ Wave EB79.4. Retrieved from http://ec.europa.eu/public_opinion/archives/eb_special_419 400 en.htm 
European Commission. (2014). Quality of transport. Special Eurobarometer 422a / Wave EB82.2 - TNS Opinion \& Social. Retrieved from http://ec.europa.eu/public_opinion/index_en.htm

Fincham, B. (2007). Bicycle messengers: Image, identity and community. In P. Rosen, P. Cox, \& D. Horton (Eds.), Cycling and society (pp. 179-195). Hampshire Ashgate.

Fraboni, F., Marin Puchades, V., De Angelis, M., Prati, G., \& Pietrantoni, L. (2016). Social influence and different types of red-light behaviors among cyclists. Frontiers in Psychology, 7(1834). doi:10.3389/fpsyg.2016.01834

Fruhen, L. S., \& Flin, R. (2015). Car driver attitudes, perceptions of social norms and aggressive driving behaviour towards cyclists. Accident Analysis \& Prevention, 83, 162-170. doi:http://dx.doi.org/10.1016/j.aap.2015.07.003

Garrard, J., Rissel, C., \& Bauman, A. (2012). Health benefits of cycling. In J. Pucher \& R. Buehler (Eds.), City Cycling (pp. 31-56). Cambridge, MA: MIT Press.

Gatersleben, B., \& Haddad, H. (2010). Who is the typical bicyclist? Transportation Research Part F: Traffic Psychology and Behaviour, 13(1), 41-48. doi:http://dx.doi.org/10.1016/j.trf.2009.10.003

Goddard, T., Kahn, K. B., \& Adkins, A. (2015). Racial bias in driver yielding behavior at crosswalks. Transportation Research Part F: Traffic Psychology and Behaviour, 33, 1-6. doi:http://dx.doi.org/10.1016/j.trf.2015.06.002

Götschi, T., Garrard, J., \& Giles-Corti, B. (2016). Cycling as a part of daily life: A review of health perspectives. Transport Reviews, 36(1), 45-71.

doi:10.1080/01441647.2015.1057877 
Granville, S., Rait, F., Barber, M., \& Laird, A. (2001). Sharing road space: Drivers and cyclists as equal road users. Edinburgh: Scottish Executive Central Research Unit.

Hamilton-Baillie, B. (2008a). Shared space: Reconciling people, places and traffic. Built Environment, 34(2), 161-181. doi:10.2148/benv.34.2.161

Hamilton-Baillie, B. (2008b). Towards shared space. URBAN DESIGN International, 13(2), 130138. doi:10.1057/udi.2008.13

Handy, S., Heinen, E., \& Krizek, K. J. (2012). Cycling in Small Cities. In J. Pucher \& R. Buehler (Eds.), City Cycling (pp. 257-286). Cambridge, MA: MIT Press.

Haworth, N., \& Debnath, A. K. (2013). How similar are two-unit bicycle and motorcycle crashes? Accident Analysis \& Prevention, 58, 15-25. doi:http://dx.doi.org/10.1016/j.aap.2013.04.014

Horton, D. (2007). Fear of Cycling. In P. Rosen, P. Cox, \& D. Horton (Eds.), Cycling and society (pp. 133-152). Hampshire Ashgate.

Jacobsen, P. L. (2003). Safety in numbers: More walkers and bicyclists, safer walking and bicycling. Injury Prevention, 9(3), 205-209. doi:10.1136/ip.9.3.205

Jacobsen, P. L., \& Rutter, H. (2012). Cycling safety. In J. Pucher \& R. Buehler (Eds.), City Cycling (pp. 141-156). Cambridge, MA: MIT Press.

Johnson, M., Oxley, J., Newstead, S., \& Charlton, J. (2014). Safety in numbers? Investigating Australian driver behaviour, knowledge and attitudes towards cyclists. Accident Analysis \& Prevention, 70, 148-154. doi:http://dx.doi.org/10.1016/j.aap.2014.02.010

Karndacharuk, A., Wilson, D. J., \& Dunn, R. (2014). A review of the evolution of shared (street) space concepts in urban environments. Transport Reviews, 34(2), 190-220. doi:10.1080/01441647.2014.893038 
Kelly, P., Kahlmeier, S., Gotschi, T., Orsini, N., Richards, J., Roberts, N., . . Foster, C. (2014). Systematic review and meta-analysis of reduction in all-cause mortality from walking and cycling and shape of dose response relationship. International Journal of Behavioral Nutrition and Physical Activity, 11, 132. doi:10.1186/s12966-014-0132-x

Kerr, N. L. (2002). When is a minority a minority? Active versus passive minority advocacy and social influence. European Journal of Social Psychology, 32(4), 471-483. doi:10.1002/ejsp.103

Lawson, A. R., Pakrashi, V., Ghosh, B., \& Szeto, W. Y. (2013). Perception of safety of cyclists in Dublin City. Accident Analysis \& Prevention, 50, 499-511. doi:http://dx.doi.org/10.1016/j.aap.2012.05.029

Macmillan, A., Connor, J., Witten, K., Kearns, R., Rees, D., \& Woodward, A. (2014). The societal costs and benefits of commuter bicycling: Simulating the effects of specific policies using system dynamics modeling. Environmental Health Perspectives, 122(4), 335-344. doi:10.1289/ehp.1307250

Mather, R. D., \& DeLucia, P. R. (2007). Testing for effects of racial attitudes and visual contrast on the speed of a driver's response to a pedestrian. Transportation Research Part F: Traffic Psychology and Behaviour, 10(6), 437-446. doi:http://dx.doi.org/10.1016/j.trf.2007.03.004

Meyers, B. (1984). Minority group: An ideological formulation. Social Problems, 32(1), 1-15. doi: $10.2307 / 800258$

Mindell, J. S., Leslie, D., \& Wardlaw, M. (2012). Exposure-based, ?Like-for-like? Assessment of road safety by travel mode using routine health data. PLoS ONE, 7(12), e50606. doi:10.1371/journal.pone.0050606 
Møller, M., \& Hels, T. (2008). Cyclists’ perception of risk in roundabouts. Accident Analysis \& Prevention, 40(3), 1055-1062. doi:http://dx.doi.org/10.1016/j.aap.2007.10.013

Moscovici, S. (1994). Three concepts: Minority, conflict, and behavioral style. In S. Moscovici, A. Mucchi-Faina, \& A. Maass (Eds.), Minority influence (pp. 233-251). Chicago, IL, US: Nelson-Hall Publishers.

OCDE/OECD. (1998). Safety of vulnerable road users. Paris: Organisation for Economic CoOperation and Development.

Parkin, J., Ryley, T., \& Jones, T. (2007). Barriers to cycling: an exploration of quantitative analyses. In P. Rosen, P. Cox, \& D. Horton (Eds.), Cycling and society (pp. 67-82). Hampshire Ashgate.

Parry, S. (2015). A theatrical gesture of disavowal: the civility of the critical mass cycle ride. Contemporary Theatre Review, 25(3), 344-356. doi:10.1080/10486801.2015.1049821

Pooley, C. G., Horton, D., Scheldeman, G., Tight, M., Jones, T., Chisholm, A., . . Jopson, A. (2011). Household decision-making for everyday travel: a case study of walking and cycling in Lancaster (UK). Journal of Transport Geography, 19(6), 1601-1607. doi:http://dx.doi.org/10.1016/j.jtrangeo.2011.03.010

Pucher, J., \& Buehler, R. (2008). Making Cycling Irresistible: Lessons from The Netherlands, Denmark and Germany. Transport Reviews, 28(4), 495-528. doi:10.1080/01441640701806612

Pucher, J., Buehler, R., \& Seinen, M. (2011). Bicycling renaissance in North America? An update and re-appraisal of cycling trends and policies. Transportation Research Part A: Policy and Practice, 45(6), 451-475. doi:http://dx.doi.org/10.1016/j.tra.2011.03.001 
Pucher, J., Komanoff, C., \& Schimek, P. (1999). Bicycling renaissance in North America?: Recent trends and alternative policies to promote bicycling. Transportation Research Part A: Policy and Practice, 33(7-8), 625-654. doi:http://dx.doi.org/10.1016/S0965$\underline{8564(99) 00010-5}$

Reid, D., \& LeBeau, P. (2016). Driverless cars still confused by cylists: Renault CEO. Retrieved from http://www.cnbc.com/2016/01/08/driverless-cars-confused-by-cyclists.html

Seyranian, V., Atuel, H., \& Crano, W. D. (2008). Dimensions of majority and minority groups. Group Processes \& Intergroup Relations, 11(1), 21-37. doi:10.1177/1368430207084843

Simon, B., Aufderheide, B., \& Kampmeier, C. (2008). The social psychology of minoritymajority relations Blackwell Handbook of Social Psychology: Intergroup Processes (pp. 303-323): Blackwell Publishers Ltd.

Simpson, G. E., \& Yinger, J. M. (1985). Racial and cultural minorities. An analysis of prejudice and discrimination. New York: Plenum.

Skinner, D., \& Rosen, P. (2007). Hell is other cyclists: Rethinking transport and identity. In P. Rosen, P. Cox, \& D. Horton (Eds.), Cycling and society (pp. 83-96). Hampshire Ashgate.

Tajfel, H. (1978). The social psychology of minorities. London: Minority Rights Group.

Tajfel, H. (1981). Human groups and social categories: Studies in social psychology. Cambridge, UK: Cambridge University Press.

Tajfel, H., \& Turner, J. C. (1986). The social identity theory of intergroup behavior. In S. Worchel \& W. Austin (Eds.), Psychology of intergroup relations (pp. 7-24). Chicago, IL: Nelson-Hall.

Titze, S., Stronegger, W. J., Janschitz, S., \& Oja, P. (2008). Association of built-environment, social-environment and personal factors with bicycling as a mode of transportation 
among Austrian city dwellers. Preventive Medicine, 47(3), 252-259.

doi:http://dx.doi.org/10.1016/j.ypmed.2008.02.019

Torbisco Casals, N. (2006). Group rights as human rights. A liberal approach to multiculturalism. Netherlands: Springer

Tsakas, N., Matsoukis, E., \& Bernhoft, I. (2010). Promoting cycling: Development aspects in two different cities, Copenhagen and Patras. In C. A. Brebbia, S. Hernández, \& E. Tiezzi (Eds.), The Sustainable City VI: Urban Regeneration and Sustainability (pp. 287-298). Southampton, UK: WIT Press.

Wagley, C., \& Harris, M. (1958). Minorities in the new world: Six case studies. New York: Columbia University Press.

Wegman, F., Zhang, F., \& Dijkstra, A. (2012). How to make more cycling good for road safety? Accident Analysis \& Prevention, 44(1), 19-29. doi:http://dx.doi.org/10.1016/j.aap.2010.11.010

Willis, D. P., Manaugh, K., \& El-Geneidy, A. (2015). Cycling under influence: Summarizing the influence of perceptions, attitudes, habits, and social environments on cycling for transportation. International Journal of Sustainable Transportation, 9(8), 565-579. doi:10.1080/15568318.2013.827285

Xia, T., Zhang, Y., Crabb, S., \& Shah, P. (2013). Cobenefits of replacing car trips with alternative transportation: A review of evidence and methodological issues. Journal of Environmental and Public Health, 2013, 14. doi:10.1155/2013/797312 